\title{
Kannabisa: ageriko altxor ezkutua
}

\section{Cannabis: a treasure trove hidden in plain sight}

\author{
Oier Aizpurua-Olaizola*, Jone Omar, Maitane Olivares, Patricia Navarro, \\ Nestor Etxebarria, Aresatz Usobiaga \\ Kimika Analitikoa Saila, Euskal Herriko Unibertsitatea (UPV/EHU), \\ Sarriena auzoa z/g, 48940 Leioa \\ *oier.aizpurua@ehu.eus
}

DOI: $10.1387 /$ ekaia.15800

Laburpena: Etorkizun hurbilean kannabisa sendagai bezala erabili ahal izateko bi urrats eman dira lan honetan. Alde batetik, landareak euren efektu fisiologikoekin lotzeko lagungarria izan daitekeen kannabinoideen hatz-marka ikertzeko metodo bat garatu da fragmentazio bikoitzeko masa-espektometriari akoplaturiko eraginkortasun handiko likido kromatografia bidez (HPLC-MS/MS High Performance Liquid chromatography-tandem mass spectrometry). Bestalde, kannabis landareko konposatuen produkzioa optimizatzeko kimiotipo ezberdineko landareen hazkuntzan zeharreko kannabinoideen eta terpenoen garapena aztertu da. Bertan, konposatu garrantzitsuenen kontzentrazio maximoak noiz agertzen diren ikusteaz gain, landare-mota bakoitzaren ezaugarri diren terpenoak zeintzuk diren aurkitu da.

Hitz gakoak: Kannabisa, hatz-marka, hazkuntza, kannabinoideak, terpenoak.

Abstract: In this work 2 different studies have been done around medical use of cannabis. On the one hand, to help to correlate plants with their physiological effects, a HPLCMS/MS method has been developed to establish the cannabinoid fingerprinting of different cannabis plants. On the other hand, in order to optimize the production of bioactive compounds, the evolution of cannabinoid and terpene content of different chemotype plants during their growth was studied. Concentration peaks for major cannabinoids and terpenes were establish and characteristic terpenes for each chemotype were identified.

Keywords: cannabis, fingerprinting, growing, cannabinoids, terpenes.

\section{SARRERA}

Lur azpiko altxorrak ondo ezkutatuta eta mila tranpaz eta amarruz babestuta daudela erakutsi izan digu Hollywood-ek, egon bada, ordea, lur az- 
Oier Aizpurua-Olaizola, Jone Omar, Maitane Olivares, Patricia Navarro, Nestor Etxebarria, Aresatz Usobiaga

pitik bere kabuz irteten den altxorrik ere. Kannabisaz ari natzaizue. Gaur egun ezagunak dira landare honek dituen hainbat ezaugarri eta erabilera; esate baterako, anorexia, minbizien fase aurreratu, edo HIES kasuetan lagungarri den gosea pizteko baliagarria dela; minbiziak sendatzeko erabiltzen den kimioterapia errazago jasateko efektu antiemetikoa duela; minbiziek, HIESak eta fibromialgia edo erreuma-artritisaren gisako gaixotasunek eragindako min neuropatiko kronikoari aurre egin diezaiokeela; eta esklerosi anizkoitzari lotutako gogortasuna edo espastizitatea tratatatzeko zein glaukoma tratatzeko erabil daitekeela [1].

Bestalde, oraindik guztiz frogatuta egon ez arren, geroz eta ikerketa zientifiko gehiagok babesten dute kannabisa beste gaixotasun askotarako irtenbide garrantzitsua izan daitekeela; hala nola, hainbat minbizi sendatzeko [1,2-5], epilepsia tratatzeko [6,7], eta alzheimerrari [8,9], Hungtintonen gaixotasunari $[10,11]$, diabetes kasuei $[12,13]$ zein Touretten sindromeari $[1,14,15]$ aurre egiteko.

Kannabisak hainbeste gaixotasunen ondorioak arintzeko balio izateak badu bere azalpen zientifikoa: sistema endokannabinoidea. Sistema hau zenbait lipido neuromodulatzailek eta euren hartzaileek osatzen dute eta gorputzeko hainbat prozesu fisiologikotan hartzen du parte; hala nola, gosean, min sentsazioan, umorean eta memorian. Lipido horiei endokannabinoide deritze eta euren hartzaileekiko selektiboak dira; hots, giltza batek sarraila batekin duen funtzio bera betetzen dute hartzaileekin. Kontua da, kannabisean aurkitzen diren kanabinoide ezberdinek ere hartzaile horiekin lotzeko gaitasuna dutela, eta, modu horretan, prozesu fisiologiko horietan guztietan eragin $[16,17]$.

Kannabisa kontsumitzeak dakartzan eragin kaltegarriei dagokienez, eragin nagusiak antsietatea eta izu-ikara egoerak dira. Landarearen toxikotasun akutua oso baxua da eta, ondorioz, sintoma ahulak eragiten ditu: arreta- eta oroimen-asaldurak edo zailtasun psikomotoreak, eta egoera larrienak autoa gidatzeko orduan gertatzen dira [1]. Eragin kronikoei dagokienez, ezaguna da, kannabisa kantitate handitan eta era kronikoan hartuz gero, bronkitis kronikoa eta zenbait asaldura histopatologiko izateko aukera asko handitzen dela [1].

Kannabis landarea ez da batere sinplea. 554 konposatutik gora identifikatu dira bertan; horien artean, 113 kannabinoide [18] eta 120 terpeno [19]. Kannabinoideak forma azidoan biosintetizatzen dira landarean, baina berotzean edo argiaren presentzian dagokien forma neutrora deskonposatzen dira. Bestalde, degradazioak ere jasan ditzakete eta beste kannabinoideetara eraldatu. Hori da kannabisaren psikoaktibitatearen eragile nagusietako bat den eta tetrahidrokannabinol azidotik (THCA tetrahydrocannabinolic acid) datorren tetrahidrokannabinolaren (THC tetrahydrocannabinol) kasua, non kannabinolera (CBN cannabinol) degrada daitekeen [20]. 113 kannabinoide 
horietako bakoitzak aktibitate terapeutiko ezberdina du eta, ondorioz, aplikazio ezberdinetarako erabil daitezke [21]. Hortaz gain, euren artean eragin sinergikoa gertatzen da; esaterako, jakina da kannabidiol azidotik (CBDA cannabidiolic acid) datorren kannabidiolak (CBD cannabidiol) THCaren eragin euforikoa modulatzen duela [22]. Hori gutxi ez, eta terpenoek, lurrinaren erantzule izateaz gain, hainbat efektu terapeutiko dituzte eta kannabinoideekin sinergian joka dezakete [23].

Milaka kannabis barietate ezagutzen dira gaur egun, eta kopurua handituz doa egunetik egunera, askotariko efektuak lortu nahian barietate ezberdinak elkarren artean gurutzatzen baitira berriak sortzeko. Dena den, ia barietate horiek guztiak kannabisaren bi azpiespezie nagusien gurutzaketetatik datoz; hots, sativatik eta indicatik. Hala, gaur egun dauden barietateak sativa modukoak, batez ere sativa modukoak, hibridoak, batez ere indica modukoak ala indica modukoak izan daitezke, duten nahastearen ehunekoaren arabera. Orain arte kaleko kulturan, azpiespezie bakoitzari justu elkarren aurkakoa den efektu jakin bat egotzi izan zaio, gainera; $s a-$ tivak THCA/CBDA ratio altuekin lotu izan direnez, estimulatzaileak eta bizigarriak direla uste izan da, eta indicak, aldiz, ratio baxuagoekin lotu izan direnez erlaxagarriak. Hala, teorikoki azpiespezie bakoitzari aplikazio jakinak aurkitzeko modua egongo litzateke. Dena den, nahiz eta morfologikoki ezberdinak izan, oraindik eztabaida dago ea kimikoki ezberdinak diren eta, ondorioz, efektu aldetik ezberdintasun agerikorik duten ala ez [24]. Bestalde, jakina da, barietate jakin bat leku ezberdinetatik eskuratuz gero, euren konposatuen kontzentrazioetan aldaketa handi samarra egoten dela [24].

Kontuak hala, landare jakinak aplikazio jakinekin lotu nahi badira, beharrezkoa da, batetik, landare estandarizatuak izatea eta, bestetik, konposatuen kontzentrazioen araberako sailkapen berri bat finkatzea. Bestalde, nahitaezkoa da konposatu bakoitzaren aktibitatea zehaztea, gainontzeko konposatuekin dituzten sinergia efektuak aztertzea eta horiek sistema endokannabinoidearekin duten elkarrekintzak zehazki nola funtzionatzen duen jakitea. Horretarako, beharrezkoa da kannabinoide zein terpeno puruak edo hauen kontzentrazio ratio jakinak dituzten landareak eskala handian ekoiztea. Bide horretan, CBDA \% 15etik gora eta THCA \% 1etik behera duen barietatea lortu zen 2014an [25].

Ildo horretan, bi urrats garrantzitsu eman dira lan honetan. Alde batetik, landareak euren efektu fisiologikoekin lotzeko lagungarria izan daitekeen kannabinoideen profila edo hatz-marka deritzona zehazteko metodo bat garatu da HPLC-MS/MS bidez [26], eta, bestetik, saiakera klinikoetan eta gainontzeko ikerketetan beharrezkoak izango diren konposatu puruen ekoizpena optimizatzeko horiek landarearen hazkuntzan zehar duten garapena ulertzeko azterketa gauzatu da [27]. 
Oier Aizpurua-Olaizola, Jone Omar, Maitane Olivares, Patricia Navarro, Nestor Etxebarria, Aresatz Usobiaga

\section{LANDAREETAKO KANNABINOIDEEN HATZ-MARKA}

Kannabis landareen kannabinoideen hatz-marka eratu ahal izateko beharrezkoa da ahalik eta kannabinoide gehien identifikatzea eta kuantifikatzea. Lan honetan 6 kannabinoide nagusi kuantifikatzeko eta beste 7 identifikatu eta kualitatiboki aztertzeko metodo analitikoa garatu da. Bestalde, metodoa baliagarria dela frogatu da 30 landare ezberdin aztertuz. Prozesu esperimentalaren eskema 1. irudian duzue ikusgai.

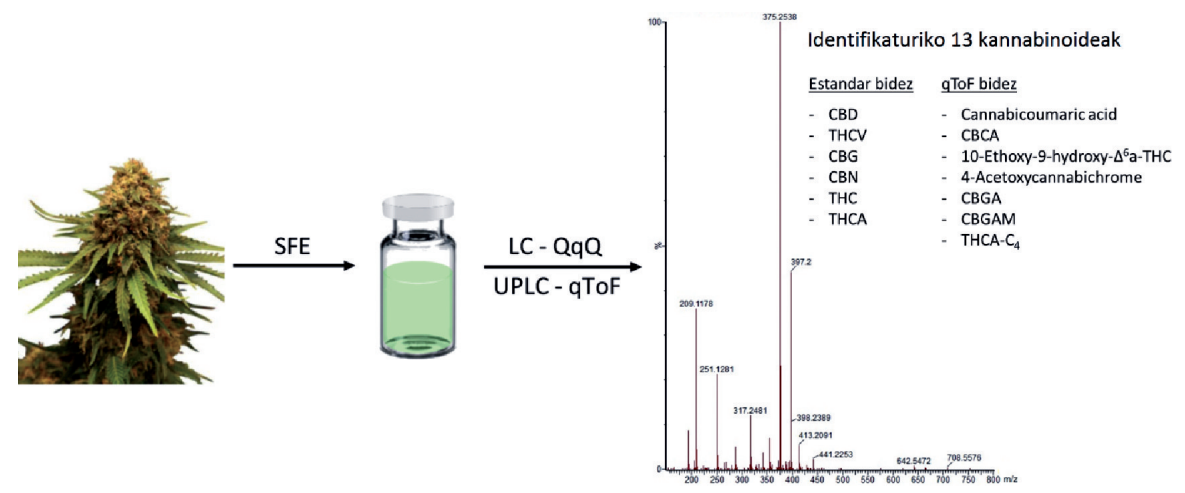

1. irudia. Kannabinoideen hatz-marka garatzeko gauzatutako prozesu esperimentalaren eskema.

Ildo honetan lehenik eta behin kannabinoideak erauzteko aurrez optimizatutako jariakin gainkritikoen bidezko erauzketa (SFE supercritical fluid extraction) erabili da, kannabinoide guztiak erauzteaz gain, lortzen diren erauzkinak purutasun altukoak baitira [28].

Bestalde, erauzkin hori aztertu ahal izateko sentikortasun handiko analisi-metodoa garatu da HPLC-MS/MS bidez. Horretarako, alde batetik, konposatuen banaketa ziurtatzeko zutabe, disolbatzaile eta gradiente egokia aurkitzeaz gain, MSeko kuadrupoloetara iritsi aurretik ekipoak dituen aldagai nagusiak optimizatu dira (kapilarreko boltajea, eluzioa lurruntzeko tenperatura, nitrogeno garraiatzailearen fluxua eta tenperatura eta langarreztagailuaren presioa). Bestalde, MSeko kuadrupoloetan analito bakoitzean gertatzen diren masa-fragmentazio nagusiak identifikatu eta horien erantzuna ahalik eta handiena izan dadin, bakoitzaren fragmentazio-potentzialak eta kolisio-energiak optimizatu dira. Modu horretan, 0,02 eta 0,2 ng/ $\mathrm{mL}$ arteko detekzio-mugak erdietsi dira kuantifikatu diren 6 kannabinoideentzat.

Kuantifikatutakoez gain, beste 7 kannabinoide identifikatzea lortu da kuadrupoloetan izan dituzten hausturak aztertuz. Euren kolisio-energiak eta 
fragmentazio-potentzialak optimizatu dira, modu horretan analito horien azterketa kualitatiboa egin ahal izateko. Identifikatutako 7 kannabinoide horiek konposatuen identifikazio zehatzagoa eskaintzen duen hegaldi-denbora bati akoplatutako kuadrupolo (Q-ToF quadrupole-time of flight) bidez berretsi dira. Teknika horrek konposatuen masa zehaztasun handiz determinatzea ahalbidetzen du, eta, modu horretan, bere formula molekularra zein den ezagut daiteke. Formula molekularra ezagututa, masa-espektroa aztertu eta bibliografiara jo da 7 kannabinoide ezezagun horiek identifikatzeko.

Behin 6 kannabinoide kuantifikatzeko eta beste 7 kualitatiboki aztertzeko metodoa garatuta, teknikaren erabilgarritasuna balioztatzeko 30 kannabis landare ezberdin aztertu dira. Datuen tratamenduari dagokionez, osagai nagusien analisia (PCA, principal component analysis) erabili da datu guztiak bildu eta landareen hatz-marka osatu ahal izateko. PCA elkarrekiko korrelazioa duten aldagai multzo bat korrelaziorik gabeko aldagai-kopuru txikiago batez laburbiltzen duen teknika da, eta helburua da hasierako aldagaien aldakortasuna osagaietan ahalik eta gehien murriztea. Aztertutako landareen kannabinoideen distribuzioa The Unscrambler programa estatistikoaren laguntzaz erdietsi da. Horretarako, HPLC-MS/MS bidez lortutako datuak normalizatu egin dira lehenik, hala, balio altu zein baxuen eragina modu berean aztertu ahal izateko.

Modu horretan, kannabis landare ezberdinak aplikazio terapeutikoekin lotzeko baliagarria izan daitekeen kanabinoideen kontzentrazioen araberako banaketa-metodoa garatu da. Metodo horren erabilgarritasunaren adierazgarri, 2. irudian ikus daiteke nola kuantifikatutako 6 kannabinoi-

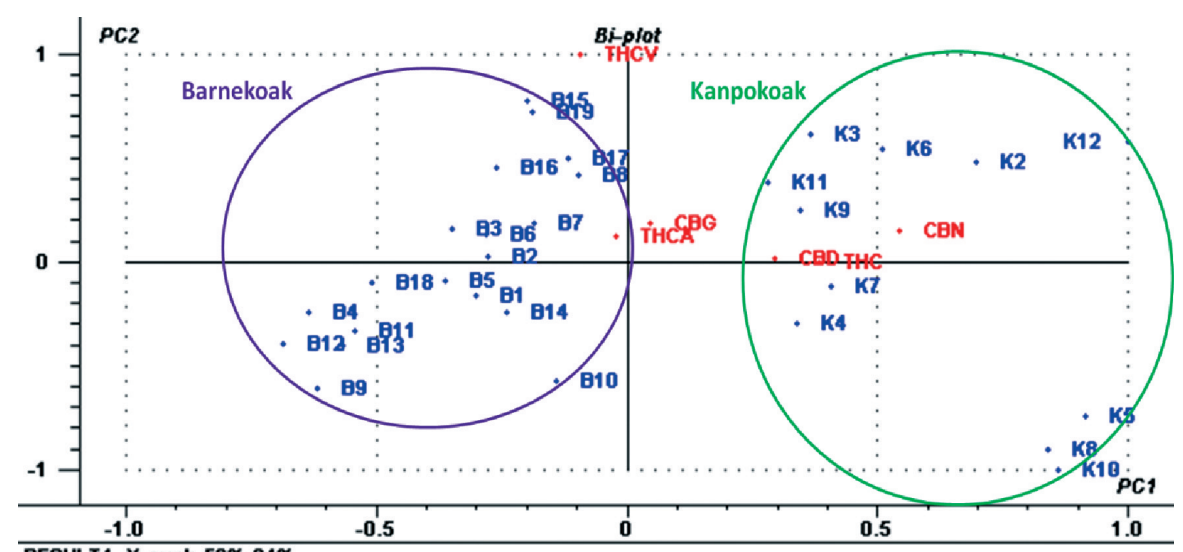

RESULT4, X-expl: 52\%,24\%

2. irudia. Cannabis sativa L. landare ezberdinen kannabinoide nagusien kontzentrazioa kontuan hartuz, osagai nagusien analisi bidez erdietsitako pisuen eta aldagaien irudikapen bikoitza (PC1 vs PC2). (B: barnean hazitako landareei dagokie; $\mathrm{K}$ : kanpoan hazitako landareei dagokie). 
Oier Aizpurua-Olaizola, Jone Omar, Maitane Olivares, Patricia Navarro, Nestor Etxebarria, Aresatz Usobiaga

deen balioak soilik erabiliz, barnean eta kanpoan hazitako landareak elkarrengandik guztiz banandu daitezkeen. Banaketa horretan gehien eragiten duen kannabinoidea $\mathrm{CBNa}$ da, THCa degradatzen denean jariatzen den konposatua, hain zuzen ere. Barnean hazitako landareen argi- eta tenperatura-baldintzak kontrolpean egoten dira, ez, ordea, kanpoan hazitakoenak. Eguraldiak izaten dituen aldaketen ondorioz, zentzuzkoa da, gertatu den bezala, kanpoan hazitako landareetan CBN kontzentrazio altuagoak aurkitzea. THC eta CBD balio handiagoak aurkitzen dira baita landare hauetan ere, baldintza gogorragoen ondorioz, euren homologo azidoak konposatu neutroetara azkarrago degradatzen baitira. THCAk, kannabigerolak (CBG) eta tetrahidrokannabibarinak (THCV tetrahydrocannabivarin), aldiz, ez dute hainbeste eragiten banaketa horretan, aldakortasun oso handia baitute landare barietate ezberdinen artean.

\section{KANNABIS LANDAREEN HAZKUNTZAREN KIMIKA}

Lan honetan kannabinoide eta terpeno nagusien garapena aztertu da 7 kannabis barietate ezberdinen hazkuntza-prozesu osoan zehar. 3 barietate THCA altukoak izan dira (I. kimiotipoa), 3 CBDA altukoak (III. kimiotipoa) eta 1 bien kontzentrazio antzekokoa (II. kimiotipoa). Horretarako, ama-landare bakoitzaren 50 klon landatu dira eta barnean hazi dira hiru fase ezberdinetan. Lehen fasean, klonak $25 \times 25$ mm-ko kubotxoetan eduki dira 18 orduko argi-zikloetan sustraiak hazi arte. Ondoren, 2 L-ko ontzietara pasa eta landareen hazkuntza gauzatu da (bigarren fasea), hauek ere 18 orduko argi-zikloetan. Azken fasean, landareak 10 L-ko ontzietara pasa eta, 12 orduko argi-zikloa ezarriz, loratzea eragin da. Astero landare bakoitzetik 3 klon moztu eta analizatu dira, 8 kannabinoide diodo-segiden detektoreari (DAD Diode Array Detector) akoplaturiko HPLC bidez eta 28 terpeno garraren bidezko ionizazio-detektagailuari loturiko gas kromatografiaren bidez (GC-FID Gas Chromatography-Flame Ionization Detector).

3. irudian islatzen da aztertutako bi kannabinoide nagusienak diren THCAk eta CBDAk, eta analizatutako monoterpeno eta seskiterpeno guztien baturek, kimiotipo ezberdinetako landareen hazkuntzan zehar izandako garapena. Bertatik ondorio asko atera daitezke. Alde batetik, THCA/ CBDA erlazioak definitzen duen landarearen kimiotipoa hasieratik agerikoa eta hazkuntzan zehar egonkorra dela. Bestalde, hostoetako kannabinoideen eta terpenoen kontzentrazioa modu garbian jaisten dela landarearen hazkuntza-fasean zehar eta, ostean, loratze-fasean berriz igo egiten dela, seskiterpenoen salbuespenarekin, hauen kontzentrazioak are gehiago jaisten jarraitzen baitu. Beste ondorio garrantzitsu bat da loreetako THCA eta CBDA kontzentrazio maximoak landarearen kimiotipoaren arabera aldatu egiten direla. Hala, I. kimiotipoko landareetan maximoa loratze-faseko 

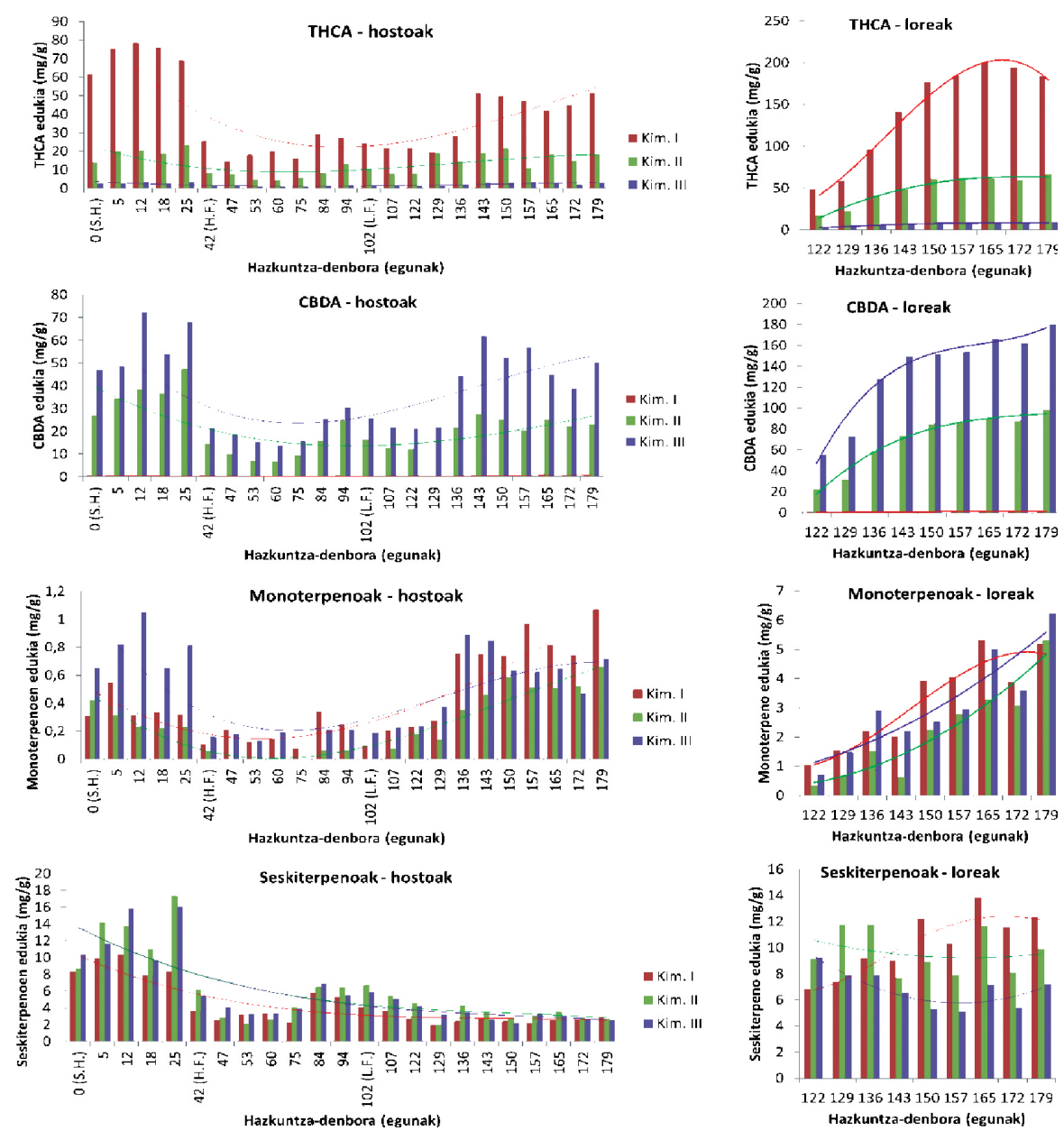

3. irudia. Landareen hazkuntza prozesuan zeharreko THCA eta CBDA kannabinoide nagusien eta monoterpeno eta seskiterpeno totalen batez besteko kontzentrazioak ikertutako 3 kimiotipo ezberdinetan, hostoetan eta loreetan. ( «S.H.» sustraien hazkuntza-faseari dagokio, «H.F.» landarearen hazkuntza-faseari eta «L.H.» loratze-faseari).

9. astean (165. eguna) aurkitzen da, II. eta III. kimiotipoetako landareetan, aldiz, kontzentrazioak gora egiten jarraitzen du ikerketaren bukaerara arte. Monoterpenoen kasuan ere antzeko joera ikusten da; ez, ordea, seskiterpenoetan, non joerak ez diren hain nabariak.

Azkenik, konposatu bakoitzaren kontzentrazio maximoa noiz gertatzen den jakiteaz gain, etorkizun hurbilean kannabinoideen eta terpenoen siner- 
Oier Aizpurua-Olaizola, Jone Omar, Maitane Olivares, Patricia Navarro, Nestor Etxebarria, Aresatz Usobiaga
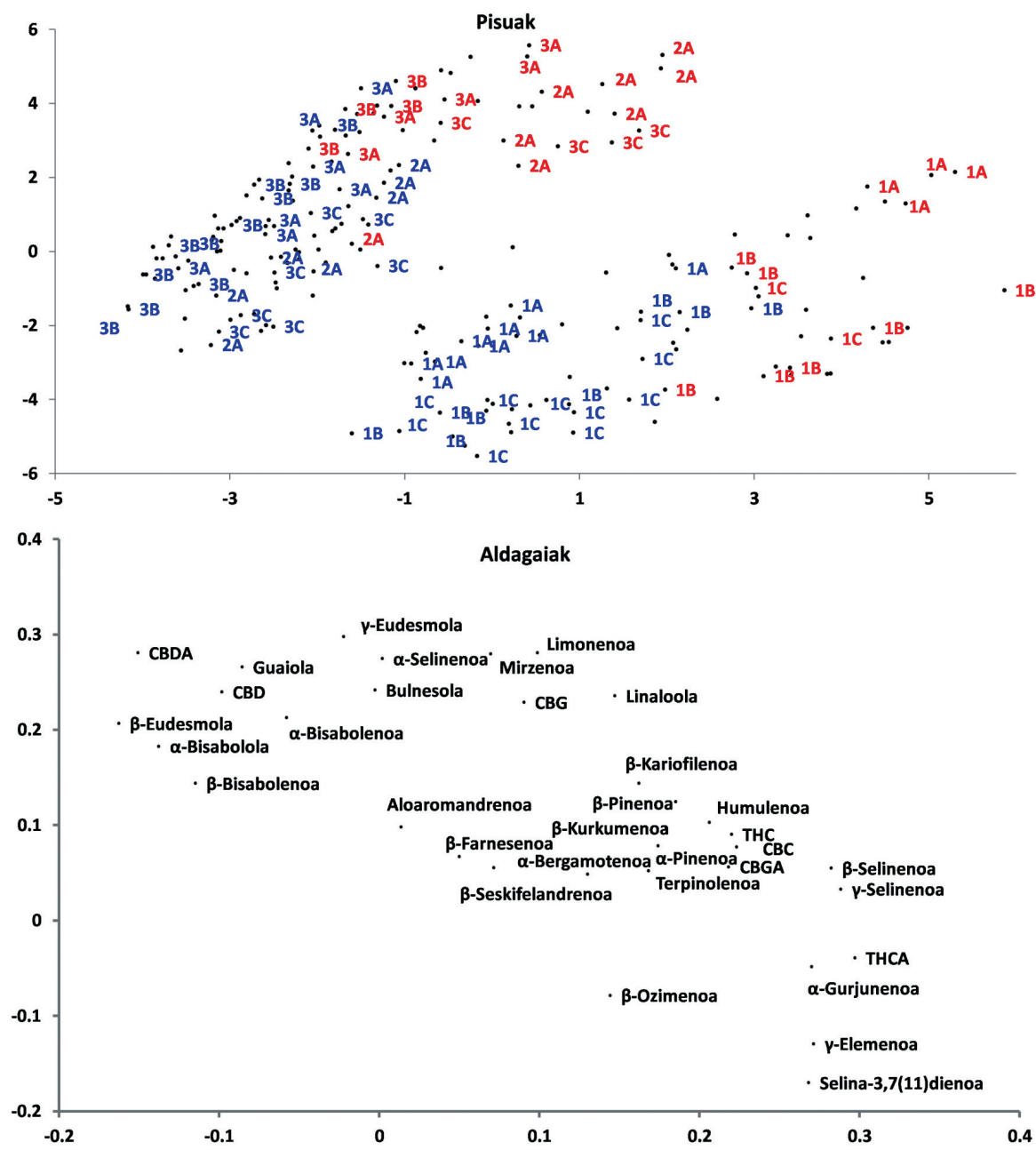

4. irudia. Landareen hazkuntzan zeharreko terpenoen edukiaren arabera, osagai nagusien analisi bidez erdietsitako pisuen eta aldagaien irudikapen bikoitza (PC1 vs PC2). (1: I. kimiotipoko landareei dagokie; 2: II. kimiotipoko landareei eta 3: III. kimiotipoko landareei; A, B eta C, ostera, kimiotipo bakoitzeko landare ezberdinak dira. Hostoen balioak urdinez ageri dira, loreenak gorriz).

giak hobeto ulertu ahal izateko ea kimiotipo bakoitzak terpeno bereizgarririk duen aztertu da. Horretarako, landareen hazkuntza prozesu osoan zehar lortutako kannabinoideen zein terpenoen kontzentrazioak PCA bidez aztertu dira. Kannabinoideen hatz-marka lortzeko metodoaren kasuan bezala, datuak normalizatu egin dira lehenik. 4. irudian pisu eta aldagaien irudikapen bikoitza duzue ikusgai. Pisuen irudikapenean, loreak eta hostoak elka- 
rrengandik bereizita agertzeaz gain, I. kimiotipoko landareak besteetatik guztiz bereizten direla ikus genezake, eta II. kimiotipoa III.etik gertuago gelditzen da, ziurrenik bere CBDA edukia THCA edukia baino handiagoa delako. Pisu horien banaketan eragin duten aldagaiei arreta jartzen badiegu, kimiotipo bakoitzaren bereizgarriak diren konposatuak zeintzuk diren ikus dezakegu. Modu horretan ikusi da, III. kimiotipoko landareetan aurrez jakina zen THCAz gain esaterako $\beta$-bisabolenoa, $\alpha$-bisabolola edo mirzenoa askoz ugariagoak direla, eta, selina-3,7(11)dienoa, $\gamma$-elemenoa edo $\alpha$-gurjunenoa, aldiz, I. kimiotipoko landareen bereizgarriak direla. II. taldeko landarea, aldiz, III. taldekoen antzekoa dela ikusi da, aurrez aipatu bezala, ziurrenik bere CBDA eduki altua dela eta.

\section{ONDORIOAK}

Kannabisa medikuntzaren munduan etorkizun handia izango duen landare bat da zalantza izpirik gabe. Oraindik bidearen zati bat egiteke dago, ordea. Ildo horretatik, bide hori gauzatzen lagunduko duten bi urrats eman dira lan honetan.

Alde batetik, landare ezberdinak aplikazio ezberdinekin lotzeko lagungarria izan daitekeen landareen kannabinoideen hatz-marka garatzeko metodo bat garatu da, eta bere erabilgarritasuna 30 landare ezberdinekin balioztatu da. Bestalde, saiakera klinikoetarako beharrezkoak diren konposizio jakineko landareen erauzkin aberatsak eta konposatu puruak kopuru handian lortzeko lagungarria izan daitekeen ikerketa gauzatu da. Bertan, kannabis landarearen 3 kimiotipo ezberdinen hazkuntza-prozesuetan zehar kannabinoide eta terpenoen kontzentrazio maximoak noiz aurkitzen diren ezartzeaz gain, kimiotipo bakoitzaren ezaugarri diren terpenoak zeintzuk diren ikusi da. Ezaugarritze hori kannabinoideen eta terpenoen arteko sinergiak aztertzea helburu duten ikerketetarako lagungarria izan daiteke.

\section{ESKER ONAK}

Egileek esker ona adierazi nahi diete Idoki SCF S.L. enpresari jariakin gainkritiko bidezko erauzketa-sistema erabiltzen uzteagatik, Aifame $\mathrm{GmbH}$ enpresari landareen hazkuntzaren ikerketarako beharrezko material eta baliabide guztiak eskaintzeagatik, eta Eusko Jaurlaritzari talde kontsolidatuko laguntzagatik (IT-742-13) eta O. Aizpurua-Olaizolaren doktoratu aurreko bekarengatik. 
Oier Aizpurua-Olaizola, Jone Omar, Maitane Olivares, Patricia Navarro, Nestor Etxebarria, Aresatz Usobiaga

\section{BIBLIOGRAFIA}

[1] HORRILLO I. eta CALLADO LF. 2013. «Kannabisaren terapia erabilera». In ZÁRATE J., (Ed.), «Kannabisaren hamar aurpegiak». Ekaia, Euskal Herria, 99-113 orr.

[2] DE PETROCELLIS L., VELLANI V., SCHIANO-MORIELLO A., MARINI P., MAGHERINI P.C., ORLANDO P. eta DI MARZO V. 2008. «Plant-derived cannabinoids modulate the activity of transient receptor potential channels of ankyrin type-1 and melastatin type-8». Journal of Pharmacology and Experimental Therapeutics, 325, 1007-1015.

[3] GALVE-ROPERH I., SÁNCHEZ C., CORTÉS M.L., GÓMEZ DEL PULGAR T., IZQUIERDO M. eta GUZMÁN M. 2000. «Anti-tumoral action of cannabinoids: involvement of sustained ceramide accumulation and extracellular signal-regulated kinase activation». Nature Medicine, 6, 313-319.

[4] PAROLARO, D. eta MASSI, P. 2008. «Cannabinoids as a potential new drug therapy for the treatment of gliomas». Expert review of neurotherapeutics, 8, 37-49.

[5] VELASCO G., SÁNCHEZ C. eta GUZMÁN M. 2012. «Towards the use of cannabinoids as antitumour agents». Nature Reviews Cancer, 12, 436-444.

[6] CUNHA J.M., CARLINI E.A., PEREIRA A.E., RAMOS O.L., PIMENTEL C., GAGLIARDI R., SANVITO W.L., LANDER N. eta MECHOULAM R. 1980. «Chronic administration of cannabidiol to healthy volunteers and epileptic patients». Pharmacology, 21, 175-185.

[7] PORTER B.E. eta JACOBSON C. 2013. «Report of a parnet survey of cannabidiol-enriched cannabis use in pediatric treatment-resistant epilepsy». Epilepsy \& Behavior, 29, 574-577.

[8] CAMPBELL V.A. eta GOWRAN A. 2007. «Alzheimer's disease; taking the edge off with cannabinoids?» British Journal of Pharmacology, 152, 655-662.

[9] EUBANKS L.M., ROGERS C.J., BEUSCHER A.E., KOOB G.F., OLSON A.J., DICKERSON T.J. eta JANDA K.D. 2006. «A molecular link between the active component of marijuana and Alzheimer's disease pathology». Molecular Pharmaceutics, 3, 773-777.

[10] LUVONE T., ESPOSITO G., DE FILIPPIS D., SCUDERI C. eta STEARDO L. 2009. «Cannabidiol: a promising drug for neurodegenerative disorders?» CNS Neuroscience \& Therapeutics, 15, 65-75.

[11] SAGREDO O., PAZOS M.R., VALDEOLIVAS S. eta FERNANDEZ-RUIZ J. 2012. «Cannabinoids: Novel Medicines for the Treatment of Huntington's Disease». Recent Patents on CNS Drug Discovery, 7, 41-48.

[12] PENNER E.A., BUETTNER H. eta MITTLEMAN M.A. 2013. «Marijuana use on glucose, insulin, and insulin resistance among US adults». American Journal of Medicine, 126, 583-589.

[13] WEISS L., ZEIRA M., REICH S., HAR-NOY M., MECHOULAM R., SLAVIN S. eta GALLILY R. 2006. «Cannabidiol lowers incidence of diabetes in non-obese diabetic mice». Autoimmunity, 39, 143-151. 
[14] MÜLLER-VAHL K.R., SCHNEIDER U., PREVEDEL H., THELOE K., KOLBE H., DALDRUP T. eta EMRICH H.M. 2003. « $\Delta 9$ tetrahydrocannabinol (THC) is effective in the treatment of tics in Tourette syndrome: a 6-week randomized trial». Journal of Clinical Psychiatry, 64, 459-465.

[15] MÜLLER-VAHL K.R., SCHNEIDER U., KOBLENZ A., JOBGES M., KOLBE H., DALDRUP T. eta EMRICH H.M. 2002. «Treatment of Tourette's syndrome with $\Delta$ 9-tetrahydrocannabinol (THC): a randomized crossover trial». Pharmacopsychiatry, 35, 57-61.

[16] MACCARRONE M., BAB I., BÍRÓ T., CABRAL G.A., DEY S.K., DI MARZO V., KONJE J.C., KUNOS G., MECHOULAM R., PACHER P., SHARKEY K.A. eta ZIMMER A. 2015. «Endocannabinoid signaling at the periphery: 50 years after THC». Trends in Pharmacological Sciences, 36, 277-296.

[17] BARRONDO S., LOPEZ DE JESÚS M., GARCIA DEL CAÑO G., GONZALEZ-BURGUERA I., ARETXABALA X., MONTAÑA M. eta SALLÉS J. 2013. «Sistema endokannabinoidea: etorkizun handiko itu terapeutikoa gaixotasun psikiatrikoetan». In ZÁRATE J., (Ed.), «Kannabisaren hamar aurpegiak». Ekaia, Euskal Herria, 115-127 orr.

[18] AHMED S.A., ROSS S.A., SLADE D., RADWAN M.M., KHAN I.A. eta ELSOHLY M.A. 2015. «Minor oxygenated cannabinoids from high potency Cannabis sativa L.» Phytochemistry. 117, 194-199.

[19] ELSOHLY M. eta SLADE D. 2005. «Chemical constituents of marijuana: the complex mixture of natural cannabinoids». Life Sciences, 78, 539-548.

[20] AIZPURUA O., OMAR J. eta ETXEBARRIA N. 2013. «Kannabis landarearen kimika». In ZÁRATE J., (Ed.), «Kannabisaren hamar aurpegiak». Ekaia, Euskal Herria, 51-65 orr.

[21] IZZO A.A., BORRELLI F., CAPASSO R., DI MARZO V. eta MECHOULAM R. 2009. «Non-psychotropic plant cannabinoids: new therapeutic opportunities from an ancient herb». Trends in Pharmacological Sciences, 30, 515-527.

[22] MCPARTLAND, J.M. eta RUSSO, E.B. 2001. «Cannabis and cannabis extracts: greater than the sum of their parts?» Journal of Cannabis Therapeutics, 1, 103-132.

[23] RUSSO E.B. 2011. «Taming THC: potential cannabis synergy and phytocannabinoid-terpenoid entourage effects». British Journal of Pharmacology, 163, 1344-1364.

[24] ELZINGA S., FISCHEDICK J., PODKOLINSKI R. eta RABER J.C. 2015. «Cannabinoids and terpenes as chemotaxonomic markers in cannabis». Natural Products Chemistry \& Research, 3: 181. doi: 10.4172/2329-6836.1000181

[25] COHEN Y. 2014. «Cannabis plant named 'avidekel'». US patent 20140259228 A1.

[26] AIZPURUA-OLAIZOLA O., OMAR J., NAVARRO P., OLIVARES M., ETXEBARRIA N. eta USOBIAGA A. 2014. «Identification and quantifica- 
Oier Aizpurua-Olaizola, Jone Omar, Maitane Olivares, Patricia Navarro, Nestor Etxebarria, Aresatz Usobiaga

tion of cannabinoids in Cannabis sativa L. plants by high performance liquid chromatography-mass spectrometry». Analytical and Bioanalytical Chemistry, 406, 7549-7560.

[27] AIZPURUA-OLAIZOLA O., SOYDANER U., ÖZTÜRK E., SCHIBANO D., SIMSIR Y., NAVARRO P., ETXEBARRIA N. eta USOBIAGA A. 2016. «Evolution of the Cannabinoid and Terpene Content during the Growth of Cannabis sativa Plants from Different Chemotypes». Journal of Natural Products, 79, 324-331.

[28] OMAR J., OLIVARES M., ALZAGA M. eta ETXEBARRIA N. 2013. «Optimisation and characterisation of marihuana extracts obtained by supercritical fluid extraction and focused ultrasound extraction and retention time locking GC-MS». Journal of Separation Science, 36, 1397-1404. 